\title{
Validasi Metode Pengujian Polychlorinated Biphenyls (PCBs) dalam Matriks Air, Padatan, dan Biota
}

\section{Validation Method for Polychlorinated Biphenyls (PCBs) Test in Water, Solids and Biota Matrices}

\author{
Yunesfi Syofyan, Retno Puji Lestari, Yuriska Andiri, dan Sri Endah Kartiningsih \\ Pusat Standardisasi Instrumen Kualitas Lingkungan Hidup (PSIKLH)-KLHK, Kawasan PUSPIPTEK Gedung \\ 210, Serpong - Tangerang Selatan 15310, T/F 021-7560981 \\ E-mail: yunesfi74@gmail.com
}

Diterima 2 Agustus 2021, direvisi 6 Oktober 2021, disetujui 14 Oktober 2021

\begin{abstract}
ABSTRAK
Validasi Metode Pengujian Polychlorinated Biphenyls (PCBs) dalam Matriks Air, Padatan, dan Biota. Polychlorinated biphenyls (PCBs) adalah senyawa kimia organoklorin buatan manusia yang berbahaya pada kesehatan manusia, mahluk hidup, dan lingkungan. Penggunaan PCBs telah dilarang secara internasional pada kesepakatan dunia dalam Konvensi Stockholm. Indonesia telah menandatangani Konvensi Stockholm pada tanggal 23 Mei 2001 dan meratifikasinya dengan Undang-Undang Nomor 19 Tahun 2009 tentang Ratifikasi Konvensi Stockholm mengenai Bahan Pencemar Organik yang Persisten. PCBs termasuk ke dalam kelompok persistent organic pollutants (POPs) yang terdaftar dalam Konvensi Stockholm, merupakan senyawa potensial sebagai penyebab kanker, mengganggu sistem imun, syaraf, reproduksi, dan kelenjar endokrin. Laboratorium Tanah dan Limbah Padat Pusat Standardisasi Instrumen Kualitas Lingkungan Hidup (PSIKLH) telah melakukan validasi metode pengujian 21 senyawa congener PCBs pada berbagai matriks lingkungan yaitu air, padatan (sedimen/tanah), dan biota sebagai bagian dari penyusunan rancangan metode standar. Pengukuran PCBs dalam sampel air, padatan, dan biota mengacu pada USEPA metode 8082A: Polychlorinated biphenyls (PCBs) by Gas Chromatography dan USEPA metode 3541: Automated Soxhlet Extraction. Modifikasi dilakukan dalam hal waktu pengujian yaitu proses ekstraksi dan clean up menggunakan alat otomatis (SOXTHERM® dan DEXTech ver 1.3). Dari waktu ekstraksi secara manual selama 18-20 jam dapat dipersingkat menjadi 2-3 jam, sedangkan untuk proses clean up membutuhkan waktu hanya 50 menit. Sampel dianalisis menggunakan instrumen Gas Chromatography - Electron Capture Detector (GC-ECD) Agilent $7890 B$ dengan program temperatur GC menggunakan kolom non polar RTx5 (id $0,25 \mu \mathrm{m}$ dan ketebalan $0,25 \mu \mathrm{m}$ ) yaitu T detektor: $300^{\circ} \mathrm{C}$, $\mathrm{T}$ kolom $70^{\circ} \mathrm{C}$, T injektor $250^{\circ} \mathrm{C}$, dan mode injeksi splitless. Validasi pengujian mengacu pada kriteria yang ditetapkan dalam Prosedur Pelaksanaan, PP 19/P3KLL tentang validasi dan verifikasi metode yang meliputi penentuan limit deteksi, uji akurasi, presisi, dan reprodusibilitas. Hasil validasi contoh uji biota memenuhi syarat keberterimaan pada 21 congener dengan hasil uji akurasi RSD $\leq 0,67$ Horwitz, sementara uji presisi dan reprodusibilitas RSD $\leq 0,5$ Horwitz. Beberapa congener yang tidak memenuhi batas keberterimaan akurasi, presisi, dan reprodusibilitas untuk matriks air antara lain 2,3-diCB (5), 2,4,6-triCB (30), dan DecaCB (209), dan pada matriks padatan (sedimen/tanah) antara lain 2,2'5-triCB (18), 2,4,5-triCB (31), dan 2,2',3,4,5-pentaCB (87). Metode ini dapat digunakan untuk pengujian PCBs untuk congener yang memenuhi syarat keberterimaan.
\end{abstract}

Kata kunci: congener, lingkungan hidup, organoklorin, persisten, polychlorinated biphenyls, validasi. 


\begin{abstract}
Validation Method for Polychlorinated Biphenyls (PCBs) Test in Water, Solids and Biota Matrices. Polychlorinated biphenyls (PCBs) are a group of manufactured organochlorine compound that have been harmful to human health, living things, and the environment. Indonesia has signed the Stockholm Convention on 23 May 2001 and ratified it through Law Number 19 of 2009 concerning Ratification of the Stockholm Convention on Persistent Organic Pollutants. PCBs are included in the group of persistent organic pollutants (POPs) listed in the Stockholm Convention, and they are dangerous compounds that potentially cause cancer and interfere with the immune, nervous, and reproductive system, and endocrine glands. Soil and Solid Waste Laboratory of PSIKLH has validated the test method for 21 $P C B$ congeners in various environmental matrices, namely water, solids (sediment/soil), and biota as a part of drafting the standard method. The PCBs measurement in water, solid samples, and biota refer to the USEPA 8082A method: Polychlorinated biphenyls (PCBS) by Gas Chromatography, and USEPA Method 3541: Automated Soxhlet Extraction. Modifications were made in terms of test time, including the extraction and cleaning process with automatic tools (SOXTHERM ${ }^{\circledR}$ and DEXTech ver 1.3). From the manual extraction time of 18-20 hours, it can be reduced to 2-3 hours, while the cleansing process takes only 50 minutes. Samples were analyzed using Gas Chromatography - Electron Capture Detector (GC-ECD) Agilent $7890 B$ with GC temperature program using RTx5 nonpolar column (id $0.25 \mu \mathrm{m}$ and $0.25 \mu \mathrm{m}$ thickness) which was set to the detector temperature of $300^{\circ} \mathrm{C}$, column temperature of $70^{\circ} \mathrm{C}$, injector temperature of $250^{\circ} \mathrm{C}$, and splitless injection mode. Validation testing refers to the criteria set out in Implementation Procedure 19/P3KLL regarding method validation and verification, which includes determination of detection limits, tests of accuracy, precision, and reproducibility. The validation results of biota test samples met the acceptance requirements for 21 congeners with the value for accuracy test of $R S D \leq 0.67$ Horwitz, while for precision and reproducibility test was $R S D \leq 0.50$ Horwitz. Several congeners failed to achieve acceptable limits for accuracy, accuracy and reproducibility in water matrix were 2,3-diCB (5), 2,4,6-triCB (30), and DecaCB (209), whereas for solids (sediment/soil) matrices were 2,2'5-triCB (18), 2,4,5-triCB (31), and 2,2',3,4,5-pentaCB (87). This method may be used to test $P C B$ s for congeners that satisfy the acceptance requirements.
\end{abstract}

Keywords: congener, environment, organochlorin, persistent, polychlorinated biphenyls, validation.

\section{Pendahuluan}

Polychlorinated biphenyls (PCBs) merupakan senyawa kimia organoklorin buatan manusia yang diidentifikasi berdampak buruk pada mahluk hidup dan lingkungan, senyawa ini tidak akan terbentuk secara alami kecuali saat terjadi kebakaran hutan (ATSDR, 2000; $\mathrm{Hu}$ et al., 2011; Loganathan \& Masunaga, 2020; Robertson \& Hansen, 2014). PCBs termasuk ke dalam kelompok persistent organic pollutants (POPs) dalam Konvensi Stockholm (UN, 2011), merupakan senyawa berbahaya yang dapat menyebabkan kanker, mengganggu sistem imun, syaraf, reproduksi, dan kelenjar endokrin (Batang et al., 2016; Norström et al., 2010). Efek merugikan PCBs diperburuk oleh sifat persistensinya, sulit terurai, dan menunjukkan waktu paruh yang lama di lingkungan (Hens \& Hens, 2018). PCBs merupakan molekul stabil yang tahan terhadap hidrolisis, oksidasi, dan perubahan suhu. PCBs tidak mudah larut dalam air tetapi larut dalam lemak, sehingga mudah terakumulasi dalam jaringan lemak hewani dan dapat diturunkan ke generasi berikutnya melalui plasenta atau ASI (Loganathan \& Masunaga, 2020). PCBs adalah polutan lintas batas yang dapat bertransportasi secara global melalui media lingkungan, baik di 
udara, air, atau spesies hewan, melewati batas negara (Silvani et al., 2019; Travis \& Hester, 1991).

PCBs merupakan senyawa yang diproduksi secara komersil sebagai campuran dalam aplikasi industri seperti fluida dielektrik pada kapasitor dan transformator, tetapi juga ditemukan sebagai pengotor dalam pelarut tinta, plastik, dan cat (ATSDR, 2000; Loganathan \& Masunaga, 2020). Manusia dan mahluk hidup lain dapat terpapar PCBs melalui makanan, minuman, udara, tanah, dan air yang terkontaminasi (Ilyas et al., 2011; Ogata et al., 2009). Berdasarkan laporan pelaksanaan inventarisasi PCBs di sektor industri yang dilakukan KLHK dan UNIDO tahun 2017, diketahui bahwa Indonesia tidak memiliki industri sintesis PCBs (Gunawan et al., 2020). Hasil inventarisasi KLHK dan UNIDO tahun 2015 dan 2016 yang dilakukan terhadap 1032 perusahaan pengguna transformator sektor industri di kota-kota besar di Pulau Jawa yang memiliki total 3015 unit menunjukkan jumlah akumulatif minyak transformator terkontaminasi PCBs $>50$ ppm sekitar 300 Ton, dan peralatan yang terkontaminasi PCBs $>50$ ppm mencapai lebih dari 1000 Ton (Gunawan et al., 2020).

Studi mengenai PCBs di lingkungan menunjukkan bahwa polutan tersebut masih ditemukan di Indonesia. Decachlorobhipenyls (PCBs 209) dan dichlorobhipenyls (PCBs 11) terdeteksi di perairan Sungai Ciliwung pada kawasan Pluit, Jakarta, dengan konsentrasi masingmasing $406 \mathrm{ng} / \mathrm{L}$ dan 6,38 ng/L (Shoiful et al., 2014). Selain air sungai, senyawa PCBs juga ditemukan pada kerang hijau (Perna viridis) dari Teluk Jakarta. Rata-rata kadar PCBs pada cangkang hijau ukuran kecil adalah $0,846 \mathrm{ppb}$, pada ukuran sedang 0,854 ppb, sedangkan pada ukuran besar adalah 2,018 ppb (Edward, 2016). Hasil investigasi kontaminasi sampah plastik di Teluk Cilacap menunjukkan rata-rata konsentrasi 61 senyawa PCBs dari lautan terbuka sebesar
$12,2 \mathrm{ng} / \mathrm{g}$ sedangkan di wilayah teluk sebesar 1,4 x $104 \mathrm{ng} / \mathrm{g}$, dengan dominasi CB6, 101, dan 173 (Bouhroum et al., 2019). Sebuah kajian mengenai konsentrasi PCBs dalam sampel sedimen di laguna Segara Anakan menunjukkan kisaran $0,11 \pm 0,05$ sampai $2,63 \pm 0,1 \mu \mathrm{g} \mathrm{kg}^{-1}$ untuk berat kering sedimen yang diduga berasal dari limbah tidak diolah yang mengalir langsung ke sungai (Azis et al., 2021).

Penggunaan PCBs telah dilarang secara internasional pada kesepakatan dunia dalam Konvensi Stockholm. Indonesia telah menandatangani konvensi tersebut pada tanggal 23 Mei 2001 dan meratifikasinya pada tahun 2009 dengan Undang-Undang Nomor 19 Tahun 2009 tentang Ratifikasi Konvensi Stockholm mengenai Bahan Pencemar Organik yang Persisten. Sebagai negara pihak konvensi, Indonesia wajib menyusun Rencana Pelaksanaan Nasional (NIP) tentang pengelolaan bahan pencemar organik yang persisten atau POPs dengan salah satu bahan yang diatur adalah PCBs. PCBs yang termasuk dalam Annex A Konvensi Stockholm, yaitu bahan kimia dengan target pelarangan penggunaan, impor, ekspor, dan harus dimusnahkan. Penggunaan PCBs di Indonesia juga telah dilarang melalui Peraturan Pemerintah No.74/2001 tentang Pengelolaan Bahan Berbahaya dan Beracun (KLHK, 2001). Dengan dikeluarkannya aturan tersebut, senyawa PCBs tidak boleh diimpor, diekspor, diproduksi, atau digunakan.

Kegiatan validasi pengujian PCBs ini bertujuan untuk menyusun metode rancangan standar nasional Indonesia (RSNI). Saat ini belum ada metode standar ataupun modifikasi dari metode standar yang lebih sederhana, aman dan ekonomis. Bila dibandingkan dengan USEPA 8082 sebagai acuan dari pengujian, waktu preparasi sampel mencapai 18-20 jam sementara metode modifikasi ini membutuhkan waktu preparasi lebih singkat yaitu 2 jam, dan lebih aman bagi analis/operator dari terpapar 
bahan kimia karena memiliki sistem tertutup.

Modifikasi terhadap metode standar membutuhkan proses validasi sesuai kriteria keberterimaan sebelum digunakan di laboratorium (BSN, 2017). Dalam SNI ISO/IEC 17025:2017, validasi merupakan konfirmasi melalui pengujian dan pengadaan bukti yang obyektif bahwa persyaratan tertentu untuk suatu maksud terpenuhi. Validasi pengujian ini mengacu pada kriteria yang ditetapkan dalam Prosedur Pelaksanaan 19/P3KLL tentang validasi dan verifikasi metode, meliputi penentuan limit deteksi, uji akurasi, presisi, dan reprodusibilitas. Pengukuran PCBs dalam sampel lingkungan ini merujuk pada USEPA metod 8082A dan metod 3541 yang dimodifikasi. Ekstraksi menggunakan SOXTHERM ${ }^{\circledR}$ dan DEXTech ver 1.3 automatic clean-up system. Hal ini dilakukan di laboratorium PSIKLH untuk membuktikan kinerja dan performa dalam melakukan pengujian PCBs.

\section{Metodologi}

\subsection{Peralatan dan bahan}

Peralatan yang digunakan adalah GC-ECD Agilent 7890B, shaker, DEXTech ver 1.3 automatic clean-up system, alat ekstraksi automatik SOXTHERM ${ }^{\circledR}$, rotary evaporator, food processor, soxlet, neraca analitik, vial, dan alat-alat gelas. Bahanbahan yang digunakan adalah standar campuran PCBs (PCBs congener mix) Restek sesuai metode IEC (International Electrotechnical Commission) yaitu IEC 61619:1997 terdiri dari 2-monoCB (1), 2,3$\operatorname{diCB}(5), 2,4,6-\operatorname{triCB}(30), 2,2$ ', 5-triCB (18), 2,4,5-triCB (31), 2,2', 5,5'-tetraCB (52), 2,2', 3,5'-tetraCB (44), 2,3, 4,4'-tetraCB (66), 2,2', 4,5,5'-pentaCB (101), 2,2',
3,4,5-pentaCB (87), 2,3,3', 4,6-pentaCB (110), 2,2', 3,5,5',6-hexaCB (151), 2,2', 4,4',5,5',-hexaCB (153), 2,2', 3,4', 5,5', -hexaCB (141), 2,2', 3,4,4', 5-hexaCB (138), 2,2', 3,4,5, 5', 6-heptaCB (187), 2, '', 3, 4,4', , , 6-heptaCB (183), 2,2', 3,4,4', 5,5'-heptaCB (180), 2,2', 3,3', 4,4', 5-heptaCB (170), 2,2',3,3',4,4', 5,5', 6-nonaCB (206), dan DecaCB (209), n-hexane p.a, aseton p.a, $\mathrm{NaCl}, \mathrm{Na}_{2} \mathrm{SO}_{4}$ anhidrat, gas $\mathrm{N}_{2}$, dan aquades. Sampel yang diuji pada validasi metode ini adalah air dan sedimen dari Muara Angke, serta sampel daging ikan mas (Cyprinus carpio) dari tempat pemancingan Muncul, Tangerang Selatan.

\subsection{Pengambilan contoh uji}

Pengambilan contoh uji matriks air dilakukan berdasarkan SNI 6989.59:2008 Pengambilan contoh uji air dan limbah (SNI, 2008), sementara untuk matriks padatan (sedimen, tanah, dan lumpur) berdasarkan SNI 8520:2018 - Pengambilan contoh uji limbah B3 padat (SNI, 2018), dan biota diambil dari lokasi tempat pemancingan.

Penanganan sampel air menurut USEPA 8082/608 meliputi holding time selama 7 hari untuk proses ekstraksi, 40 hari setelah ekstraksi untuk analisis, minimal volume sampel sebanyak $1 \mathrm{~L}$, tipe wadah amber glass, dan preservasi pada $0-6^{\circ} \mathrm{C}$. Bila di lokasi pengambilan contoh uji terdapat klorin residu, maka $\mathrm{Na}_{2} \mathrm{~S}_{2} \mathrm{O}_{3}$ harus ditambahkan pada sampel.

Penanganan sampel padat meliputi holding time selama 14 hari untuk proses ekstraksi, 40 hari setelah ekstraksi untuk analisis, minimal jumlah sampel sebanyak $30 \mathrm{~g}$, tipe wadah gelas dengan tutup Teflon, dan preservasi pada $0-6^{\circ} \mathrm{C}$.

Penanganan sampel ikan dilakukan

Tabel 1. Informasi sampel

\begin{tabular}{lll}
\hline Lokasi & GPS & Matriks \\
\hline Muara Angke & S 06 $06^{\prime} 35,90^{\prime \prime}$ E 106 $46^{\circ}$ '27,70” & air, sedimen \\
Muncul & S 06 $200^{\prime} 59,07^{\prime \prime}$ E 106 $100^{\prime} 09,46^{\prime}$ & biota (ikan) \\
\hline
\end{tabular}


dengan membekukan daging yang sudah dipisahkan dari bagian lainnya sebelum dianalisis. Sampel dibiarkan pada suhu ruang terlebih dahulu, sebelum dianalisis dan dapat disimpan selama 40 hari setelah diekstraksi.

\subsection{Analisis}

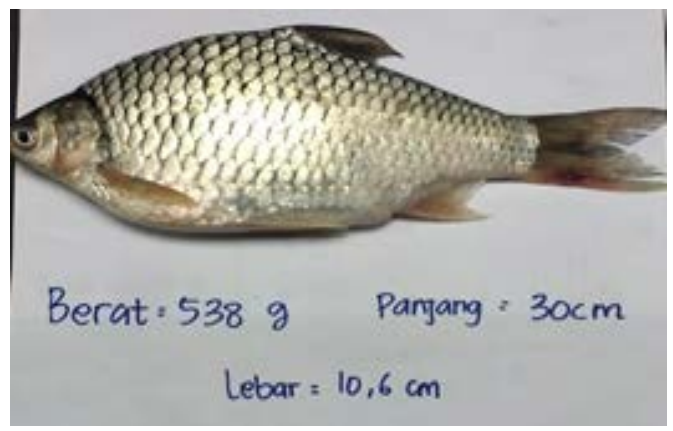

Gambar 1. Sampel ikan mas

\subsubsection{Sampel air}

Sebanyak $1 \mathrm{~L}$ air diekstraksi dengan $50 \mathrm{ml}$ hexane dan $30 \mathrm{~g} \mathrm{NaCl}$ menggunakan shaker selama 10 menit, kedua fase dipisahkan dan fase hexane ditampung. Fase air diekstrak kembali dengan $50 \mathrm{ml}$ hexane selama 10 menit. Fase hexane dari kedua hasil ekstraksi dicampurkan dan dibilas dengan air $100 \mathrm{ml}$. Fase hexane total dipekatkan menjadi $5 \mathrm{ml}$ menggunakan rotary evaporator. Larutan ekstraksi dipindahkan ke dalam botol 20 ml, kemudian dimurnikan menggunakan alat DEXTech. Hasil ekstraksi dimurnikan menjadi kurang dari $1 \mathrm{ml}$ kemudian dipindahkan dalam tabung $10 \mathrm{ml}$. Larutan ditepatkan dengan hexane sebelum diinjeksikan ke GC-ECD. Program temperatur GC-ECD menggunakan kolom nonpolar RTx5 (id 0,25 $\mu \mathrm{m}$ dan ketebalan 0,25 $\mu \mathrm{m}$ ) dengan $\mathrm{T}$ detektor: $300 \mathrm{oC}, \mathrm{T}$ kolom $70^{\circ} \mathrm{C}, \mathrm{T}$ injektor $250^{\circ} \mathrm{C}$, mode injeksi: splitless.

\subsubsection{Sampel padatan}

Sampel padatan dikeringanginkan di temperatur ruangan sebelum ditimbang. Sebanyak 5 g sampel ditambah $5 \mathrm{~g} \mathrm{Na}_{2} \mathrm{SO}_{4}$ anhidrat diekstraksi menggunakan campuran $150 \mathrm{ml}$ Hex:Ac (1:1) menggunakan alat automatik SOXTHERM ${ }^{\circledR}$ selama 2,5 jam (spesifikasi program T-classification $200^{\circ} \mathrm{C}$, $\mathrm{T}$ ekstraksi $100^{\circ} \mathrm{C}$, interval reduksi 3 menit 30 detik, durasi ekstraksi panas 1 jam, evaporasi A 4x interval, durasi ekstraksi kedua 1 jam, evaporasi B 2x interval, evaporasi C 10 menit) (spesifikasi program T-classification $200^{\circ} \mathrm{C}, \mathrm{T}$ ekstraksi $100^{\circ} \mathrm{C}$, interval reduksi 3 menit 30 detik, ekstraksi 1 jam, evaporasi A 4x interval, waktu ekstraksi kedua 1 jam, evaporasi $\mathrm{B} 2 \mathrm{x}$ interval, evaporasi C 10 menit) sampai volume akhir mencapai $\pm 5 \mathrm{ml}$. Hasil ekstraksi dimurnikan menggunakan DEXTech menjadi kurang dari $1 \mathrm{ml}$ kemudian dipindahkan dalam tabung $10 \mathrm{ml}$. Larutan ditepatkan dengan hexane sebelum diinjeksikan ke GC-ECD. Program temperatur GC-ECD menggunakan kolom nonpolar RTx5 (id $0,25 \mu \mathrm{m}$ dan ketebalan $0,25 \mu \mathrm{m})$ dengan $\mathrm{T}$ detektor: $300^{\circ} \mathrm{C}, \mathrm{T}$ kolom $70^{\circ} \mathrm{C}$, T injektor $250^{\circ} \mathrm{C}$, mode injeksi: splitless.

\subsubsection{Sampel biota}

Sampel biota (ikan) diukur panjangnya dan ditimbang beratnya. Pengujian ini menggunakan bagian daging dari ikan. Daging ikan dipisahkan dari bagian lain dan dihancurkan menggunakan food processor sampai halus. Sebanyak $5 \mathrm{~g}$ sampel ditimbang dan selanjutnya diperlakukan sama dengan prosedur pengujian sampel padatan.

\subsection{Perhitungan}

Konsentrasi masing-masing senyawa congener PCBs diperoleh dari hasil perhitungan melalui kurva kalibrasi melalui persamaan regresi linear: $y=a x+b$.

\subsection{Validasi metode}

Kriteria validasi metode yang mengacu pada PP 19/P3KLL dibagi menjadi penentuan IDL yaitu dengan menginjeksikan standar terkecil 10 ppb sebanyak 7 kali, kemudian 
dihitung berdasarkan persamaan IDL = 3xSD. Penentuan MDL dilakukan dengan melakukan 7 kali pengulangan sampel yang diukur dengan spiked sampel, $\mathrm{MDL}=$ 3,14xSD. Penentuan LoQ dihitung dengan mengukur 7 kali pengulangan sampel, LoQ $=10 \mathrm{xSD}$ dengan kriteria penerimaan sebagai berikut: MDLx10 $>$ spike, MDL $<$ spike, MDL $<$ baku mutu, \%R=70-125\%, \%RSD $\leq 2 / 3$ Horwitz. Uji presisi (\%RSD) harus memenuhi kriteria $<0,5$ Horwitz. Uji akurasi dilakukan dengan menambahkan larutan standar campuran PCBs di awal preparasi sampel menjadi konsentrasi tertentu. Kriteria keberterimaan berdasarkan APHA (2017) yaitu \% kedapatulangan adalah 60$140 \%$. Uji reprodusibilitas dilakukan oleh 2 orang analis berbeda pada waktu berbeda dengan peralatan yang sama. Tiap analis melakukan uji verifikasi, RSD dan nilai Horwitz dihitung berdasarkan rata-rata hasil uji dari analis 1 dan analis 2, dengan kriteria $\mathrm{RSD}<0,67$ Horwitz. Kompetensi analis dihitung dengan menghitung SD dan menentukan uji F (AOAC, 2016).

\section{Hasil dan Pembahasan}

Pengukuran PCBs dalam sampel padatan dan biota mengacu pada USEPA metode 8082A dan metode 3541 yang dimodifikasi yaitu merubah beberapa bagian prosedur khususnya pada proses preparasi. Sokletasi otomatis menggunakan alat SOXTHERM ${ }^{\circledR}$ dan proses clean up menggunakan Dextech dapat mengurangi waktu pengerjaan preparasi sehingga tahap pengujian menjadi lebih sederhana dan aman. Dextech merupakan peralatan canggih denga harga cukup mahal. Adapun kekurangan metode modifikasi ini adalah proses preparasi tersebut membutuhkan volume pelarut yang banyak serta kolom clean up yang hanya sekali pakai sehingga menjadi kurang ekonomis. Metode ekstraksi dan clean-up sampel tingkat lanjut (advanced) sangat dibutuhkan untuk pengembangan metode PCBs dengan memperhatikan prosedur analisis ramah lingkungan (Reddy, Moniruzzaman, Madhavi, \& Aminabhavi, 2020).

Penggunaan SOXTHERM® telah banyak dilakukan untuk ekstraksi berbagai sampel makanan antara lain minyak dedak padi (rice bran oil) (Daud et al., 2018), tepung (Ananthu \& Singh, 2018), biji semangka (Poornima, Hanumantharaju, Siva Shankar, Suresh Kumar, \& Ramya, 2019), biji bunga matahari (Shorstkii, Khudyakov, \& Mirshekarloo, 2020) dan lain-lain. SOXTHERM ${ }^{\circledR}$ juga berfungsi dengan sangat baik pada ekstraksi minyak lemak (fatty oil) dalam berbagai jenis sampel (Altan \& Turan, 2016; Antony Jesu Prabhu et al., 2018; Đurović et al., 2018; Lush, Ward, \& Wheeler, 2014).

Dalam kajian ini disampaikan salah satu contoh perhitungan validasi metode parameter 2,4,6-triCB (30) dalam matriks padatan (sedimen) dengan rentang pengukuran 10-500 ppb dalam pembuatan kurva kalibrasi. Hasil pengukuran dihitung untuk mencari persamaan garis dan linearitas seperti terlihat pada Tabel 2 dan Gambar 2.

Tahapan validasi metode dilakukan dengan pembuatan kurva kalibrasi pada rentang kerja metode untuk menghitung batas deteksi metode (Method Limit Detection, MDL) dan batas kuantifikasi (Limit of Quantitation, LoQ) melalui pengujian

Tabel 2. Penentuan kurva kalibrasi dan slope metode parameter 2,4,6-triCB (30)

\begin{tabular}{lcl}
\hline No & Konsentrasi $(\mathrm{ng} / \mathrm{ml})$ & \multicolumn{1}{c}{ Area } \\
\hline 1. & 10 & 1998,0318 \\
2. & 50 & 8035,43701 \\
3. & 100 & 15220,8000 \\
4. & 200 & 28968,5000 \\
5. & 500 & 69821,7000 \\
\hline Method slope & 137,7860 \\
Intercept & 1109,7004 \\
Correlation determination $(\mathrm{R})$ & 0,998 \\
Correlation coefficient $(\mathrm{r})$ & 0,9999 \\
Batas keberterimaan & $\mathrm{r} \geq 0,995$ \\
Kesimpulan Linearitas & Diterima \\
\hline
\end{tabular}




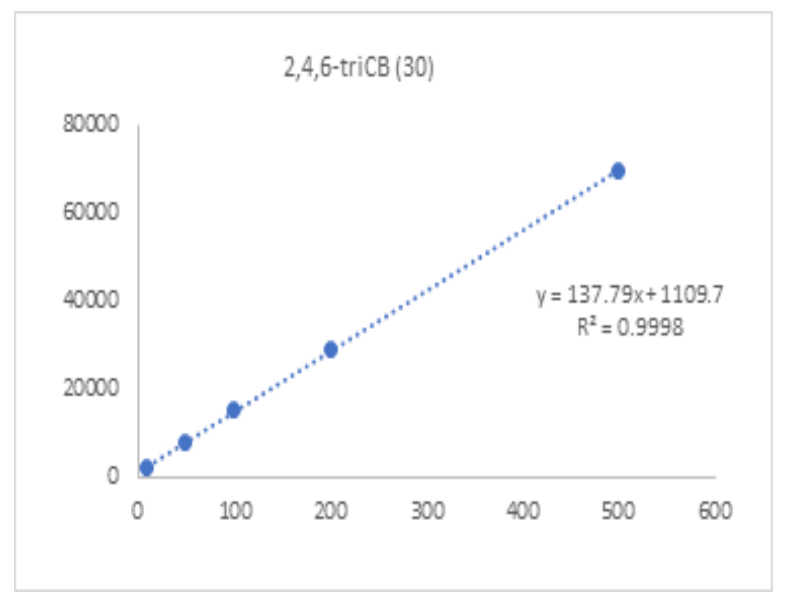

Gambar 2. Kurva kalibrasi 2,4,6-triCB (30)

Tabel 3. Penentuan Method Detection Limit (MDL) dan Limit of Quantification (LoQ)

\begin{tabular}{|c|c|c|c|c|}
\hline Pengulangan sampel & $\begin{array}{l}\text { C sampel } \\
(\mathrm{ng} / \mathrm{g})\end{array}$ & $\begin{array}{l}\text { C spike } \\
\text { (ng/g) }\end{array}$ & $\begin{array}{c}\text { C target } \\
(\mathrm{ng} / \mathrm{g})\end{array}$ & Recovery (\%) \\
\hline 1 & 0,4272 & 10,9961 & 10,5689 & 111,53 \\
\hline 2 & 5,3973 & 17,5238 & 12,1265 & 97,21 \\
\hline 3 & 10,6691 & 20,7332 & 10,0641 & 117,13 \\
\hline 4 & 10,1941 & 21,8301 & 11,6360 & 101,31 \\
\hline 5 & 4,9175 & 19,8324 & 14,9150 & 79,03 \\
\hline 6 & 0,7947 & 13,2300 & 12,4353 & 94,79 \\
\hline 7 & 16,0258 & 26,4579 & 10,4320 & 113,00 \\
\hline Rerata & & & 11,740 & 102,00 \\
\hline Standar deviasi (SD) & & & 1,664 & \\
\hline $\mathrm{MDL}=3,143 \times \mathrm{SD}$ & & & 5,230 & \\
\hline $\mathrm{LoQ}=10 \times \mathrm{SD}$ & & & 16,641 & \\
\hline$\% \mathrm{RSD}$ & & & 14,175 & \\
\hline \multicolumn{5}{|c|}{ Batas keberterimaan } \\
\hline \multirow{2}{*}{\multicolumn{2}{|c|}{$\begin{array}{l}\text { 1) } 10 \% \text { spike }<\text { MDL }<\text { spike } \\
\text { 2) } \% \mathrm{R}=70-125 \%\end{array}$}} & $1,18<5,230<11,79$ & diterima & \\
\hline & & $102,00 \%$ & diterima & \\
\hline \multicolumn{2}{|c|}{ 3) $\% \mathrm{RSD} \leq 0,67$ Horwitz } & $14,175<20,929$ & diterima & \\
\hline \multicolumn{2}{|c|}{ Kesimpulan MDL } & & $5,230 \mathrm{r}$ & \\
\hline \multicolumn{2}{|l|}{ Kesimpulan LoQ } & & 16,641 & \\
\hline
\end{tabular}

Tabel 4. Repitabilitas, Reprodusibilitas, dan Akurasi

\begin{tabular}{|c|c|c|}
\hline Ulangan & Hasil analis $1(\mathrm{ng} / \mathrm{g})$ & Hasil analis $2(\mathrm{ng} / \mathrm{g})$ \\
\hline 1 & 11,2349 & 9,9525 \\
\hline 2 & 10,8990 & 11,2225 \\
\hline 3 & 15,3359 & 10,3710 \\
\hline 4 & 12,0024 & 10,6103 \\
\hline 5 & 10,4320 & 13,8548 \\
\hline 6 & 11,9882 & 10,6099 \\
\hline 7 & 10,1208 & 13,9150 \\
\hline Rata-rata & 11,716 & 11,505 \\
\hline Standar deviasi (SD) & 1,7489 & 1,669 \\
\hline$\%$ RSD & 14,927 & 14,504 \\
\hline Nilai Horwitz & 31,25 & 31,33 \\
\hline
\end{tabular}


Tabel 4. Lanjutan

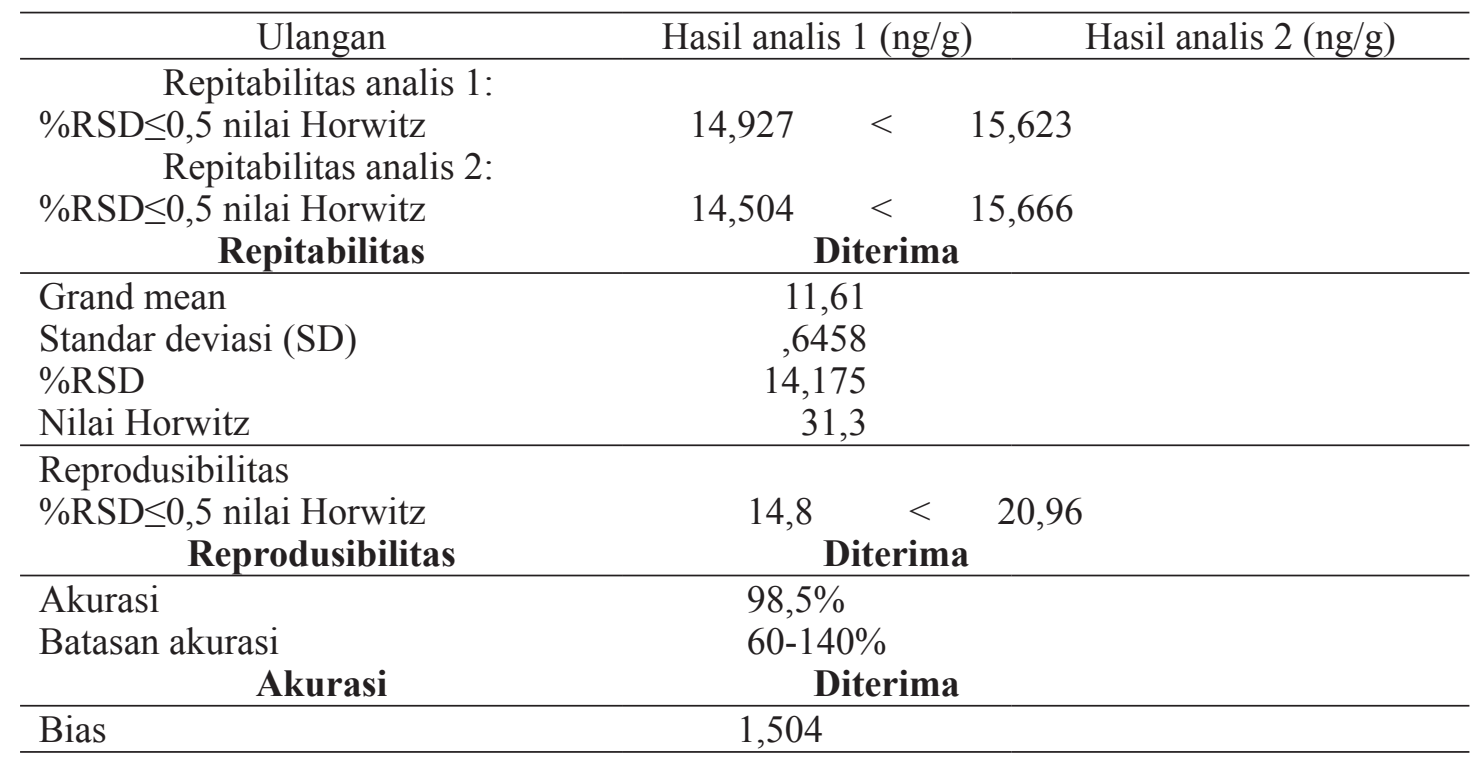

presisi dan akurasi dengan menambahkan larutan spike sebesar 11,79 ng/g ke dalam contoh uji.

Dengan merujuk contoh perhitungan Tabel 4., validasi metode parameter PCBs menggunakan instrumen GC-ECD Agilent 7890B untuk tiap matriks dirangkum dalam Tabel 5, Tabel 6 dan Tabel 7.

Pemilihan parameter PCBs yang terdiri dari 21 congeners ini mengacu pada

Tabel 5. Hasil validasi metode PCBs dalam air

\begin{tabular}{|c|c|c|c|c|c|}
\hline \multirow{2}{*}{ Nama senyawa } & \multicolumn{3}{|c|}{ Kriteria keberterimaan } & \multirow{2}{*}{$\begin{array}{l}\text { MDL } \\
(\mathrm{ng} / \mathrm{ml})\end{array}$} & \multirow{2}{*}{$\begin{array}{c}\text { LOQ } \\
(\mathrm{ng} / \mathrm{ml})\end{array}$} \\
\hline & Presisi & Akurasi & Reprodusibilitas & & \\
\hline 2-monoCB (1) & $\sqrt{ }$ & $\sqrt{ }$ & $\sqrt{ }$ & 0.009 & 0,03 \\
\hline 2,3-diCB (5) & $\mathrm{x}$ & $\mathrm{x}$ & $\mathrm{x}$ & - & - \\
\hline 2,4,6-triCB (30) & $\mathrm{x}$ & $\mathrm{x}$ & $\mathrm{x}$ & - & - \\
\hline 2,2’,5-triCB (18) & $\sqrt{ }$ & $\sqrt{ }$ & $\sqrt{ }$ & 0.01 & 0,04 \\
\hline 2,4,5-triCB (31) & $\sqrt{ }$ & $\sqrt{ }$ & $\sqrt{ }$ & 0,005 & 0,02 \\
\hline 2,2',5,5’-tetraCB (52) & $\sqrt{ }$ & $\sqrt{ }$ & $\sqrt{ }$ & 0.008 & 0,03 \\
\hline 2,2’,3,5-tetraCB (44) & $\sqrt{ }$ & $\sqrt{ }$ & $\sqrt{ }$ & 0,003 & 0,01 \\
\hline 2,3,4,4’-tetraCB (66) & $\sqrt{ }$ & $\sqrt{ }$ & $\sqrt{ }$ & 0,006 & 0,02 \\
\hline 2,2’,4,5,5'-pentaCB (101) & $\sqrt{ }$ & $\sqrt{ }$ & $\sqrt{ }$ & 0,003 & 0,01 \\
\hline 2,2’,3,4,5-pentaCB (87) & $\sqrt{ }$ & $\sqrt{ }$ & $\sqrt{ }$ & 0,01 & 0,04 \\
\hline 2,3,3’,4,6-pentaCB (110) & $\sqrt{ }$ & $\sqrt{ }$ & $\sqrt{ }$ & 0,01 & 0,04 \\
\hline 2,2',3,5,5',6-hexaCB (151) & $\sqrt{ }$ & $\sqrt{ }$ & $\sqrt{ }$ & 0,005 & 0,02 \\
\hline $2,2^{\prime}, 4,4^{\prime}, 5,5^{\prime}-$ hexaCB (153) & $\sqrt{ }$ & $\sqrt{ }$ & $\sqrt{ }$ & 0,01 & 0,03 \\
\hline 2,2',3,4,5,5'-hexaCB (141) & $\sqrt{ }$ & $\sqrt{ }$ & $\sqrt{ }$ & 0,008 & 0,03 \\
\hline 2,2',3,4,4',5-hexaCB (138) & $\sqrt{ }$ & $\sqrt{ }$ & $\sqrt{ }$ & 0,01 & 0,03 \\
\hline 2,2',3,4,5,5',6-heptaCB (187) & $\sqrt{ }$ & $\sqrt{ }$ & $\sqrt{ }$ & 0,008 & 0,02 \\
\hline 2,2',3,4,4',5,6-heptaCB (183) & $\sqrt{ }$ & $\sqrt{ }$ & $\sqrt{ }$ & 0,007 & 0,02 \\
\hline $2,2^{\prime}, 3,4,4^{\prime}, 5,5^{\prime}$-heptaCB (180) & $\sqrt{ }$ & $\sqrt{ }$ & $\sqrt{ }$ & 0,004 & 0,01 \\
\hline 2,2’,3,3’,4,4',5-heptaCB (170) & $\sqrt{ }$ & $\sqrt{ }$ & $\sqrt{ }$ & 0,008 & 0,02 \\
\hline $2,2^{\prime}, 3,3^{\prime}, 4,4^{\prime}, 5,5^{\prime}, 6$-nonaCB (206) & $\sqrt{ }$ & $\sqrt{ }$ & $\sqrt{ }$ & 0,02 & 0,07 \\
\hline DecaCB (209) & $\mathrm{x}$ & $\mathrm{x}$ & $\mathrm{x}$ & 0,02 & 0,07 \\
\hline
\end{tabular}


Tabel 6. Hasil validasi metode PCBs dalam sedimen/tanah

\begin{tabular}{|c|c|c|c|c|c|}
\hline \multirow[t]{2}{*}{ Nama senyawa } & \multicolumn{3}{|c|}{ Kriteria keberterimaan } & \multirow{2}{*}{$\begin{array}{c}\text { MDL } \\
(\mathrm{ng} / \mathrm{ml})\end{array}$} & \multirow{2}{*}{$\begin{array}{r}\mathrm{LOQ} \\
(\mathrm{ng} / \mathrm{ml})\end{array}$} \\
\hline & Presisi & Akurasi & Reprodusibilitas & & \\
\hline 2-monoCB (1) & $\sqrt{ }$ & $\sqrt{ }$ & $\sqrt{ }$ & 6 & 18 \\
\hline 2,3-diCB (5) & $\sqrt{ }$ & $\sqrt{ }$ & $\sqrt{ }$ & 5 & 16 \\
\hline 2,4,6-triCB (30) & $\sqrt{ }$ & $\sqrt{ }$ & $\sqrt{ }$ & 5 & 17 \\
\hline $2,2^{\prime}, 5$-triCB $(18)$ & $\mathrm{x}$ & $\mathrm{x}$ & $\mathrm{x}$ & 11 & 15 \\
\hline 2,4,5-triCB (31) & $\mathrm{x}$ & $\mathrm{x}$ & $\sqrt{ }$ & 8 & 10 \\
\hline 2,2',5,5'-tetraCB (52) & $\sqrt{ }$ & $\sqrt{ }$ & $\sqrt{ }$ & 6 & 18 \\
\hline 2,2',3,5-tetraCB (44) & $\sqrt{ }$ & $\sqrt{ }$ & $\sqrt{ }$ & 7 & 10 \\
\hline 2,3,4,4'-tetraCB (66) & $\sqrt{ }$ & $\sqrt{ }$ & $\sqrt{ }$ & 3 & 10 \\
\hline $2,2^{\prime}, 4,5,5^{\prime}$-pentaCB $(101)$ & $\sqrt{ }$ & $\sqrt{ }$ & $\sqrt{ }$ & 2 & 7 \\
\hline 2,2',3,4,5-pentaCB (87) & $\mathrm{x}$ & $\mathrm{x}$ & $\mathrm{x}$ & 7 & 10 \\
\hline 2,3,3',4,6-pentaCB (110) & $\sqrt{ }$ & $\sqrt{ }$ & $\sqrt{ }$ & 5 & 17 \\
\hline 2,2',3,5,5',6-hexaCB (151) & $\sqrt{ }$ & $\sqrt{ }$ & $\sqrt{ }$ & 3 & 11 \\
\hline 2,2',4,4',5,5'-hexaCB (153) & $\sqrt{ }$ & $\sqrt{ }$ & $\sqrt{ }$ & 3 & 10 \\
\hline 2,2’,3,4,5,5’-hexaCB (141) & $\sqrt{ }$ & $\sqrt{ }$ & $\sqrt{ }$ & 3 & 11 \\
\hline $2,2^{\prime}, 3,4,4^{\prime}, 5-$-ехаCB (138) & $\sqrt{ }$ & $\sqrt{ }$ & $\sqrt{ }$ & 3 & 8 \\
\hline 2,2',3,4,5,5',6-heptaCB (187) & $\sqrt{ }$ & $\sqrt{ }$ & $\sqrt{ }$ & 3 & 10 \\
\hline 2,2',3,4,4',5,6-heptaCB (183) & $\sqrt{ }$ & $\sqrt{ }$ & $\sqrt{ }$ & 2 & 7 \\
\hline 2,2',3,4,4',5,5'-heptaCB (180) & $\sqrt{ }$ & $\sqrt{ }$ & $\sqrt{ }$ & 3 & 9 \\
\hline 2,2',3,3’,4,4',5-heptaCB (170) & $\sqrt{ }$ & $\sqrt{ }$ & $\sqrt{ }$ & 4 & 11 \\
\hline $2,2^{\prime}, 3,3^{\prime}, 4,4^{\prime}, 5,5^{\prime}, 6$-nonaCB (206) & $\sqrt{ }$ & $\sqrt{ }$ & $\sqrt{ }$ & 3 & 9 \\
\hline DecaCB (209) & $\sqrt{ }$ & $\sqrt{ }$ & $\sqrt{ }$ & 6 & 9 \\
\hline
\end{tabular}

metode IEC 61619: 1997 Insulating liquids Contamination by polychlorinated biphenyls (PCBs) - Method of determination by capillary column gas chromatography yaitu untuk jenis-jenis PCBs yang terkandung dalam minyak pada transformator.

Pada validasi sampel air menunjukkan bahwa terdapat 3 congeners yang tidak memenuhi kriteria keberterimaan, yaitu 2,3diCB (5), 2,4,6-triCB (30), dan Deca CB (209). Peak 2,3-diCB (5) dan 2,4,6-triCB (30) sama sekali tidak terdeteksi dalam kromatogram. Hal tersebut diduga karena senyawa ini mengalami kerusakan selama proses preparasi. Senyawa Deca CB (\#209) terdeteksi, namun tidak memenuhi batas keberterimaan. Secara umum, metode ini dapat digunakan untuk analisis PCBs dalam air. Nilai LOQ dari 21 senyawa PCBs dalam matriks air berkisar antara 0,01-0,07 ng/ml. Dalam PP No 22/2021 Lampiran VI, baku mutu PCBs dalam air tidak dipersyaratkan.
Pada matriks sedimen, senyawa $2,2^{\prime}$, 5-triCB (18) dan 2,2', 3,4,5-pentaCB (87) tidak memenuhi krteria keberterimaan pada uji presisi dan reprodusibilitas tetapi menenuhi uji akurasi. Senyawa 2,4,5-triCB (31) hanya memenuhi uji reprodusibilitas dan akurasi, tetapi tidak memenuhi uji presisi. Namun demikian, secara umum metode ini dapat diaplikasikan pada sampel sedimen/tanah. Nilai LOQ dari 21 senyawa PCBs dalam matriks sedimen/tanah berkisar antara 7-18 ng/g atau MDL sebesar 1-11 ng/g yang berada di bawah nilai baku mutu tanah tercemar sesuai lampiran XIII PP 22 Tahun 2021 dengan kriteria TK-A = $50 \mathrm{mg} /$ $\mathrm{Kg}, \mathrm{TK}-\mathrm{B}=2 \mathrm{mg} / \mathrm{Kg}, \mathrm{TK}-\mathrm{C}=0,02 \mathrm{mg} / \mathrm{Kg}$.

Validasi sampel biota (ikan) menunjukkan hasil yang baik dalam kriteria keberterimaan (presisi, akurasi, dan reprodusibilitas) untuk seluruh parameter senyawa congener PCBs yang diujikan, seperti terlihat pada Tabel 6. Nilai LOQ 
Tabel 7. Hasil validasi metode PCBs dalam biota (ikan)

\begin{tabular}{|c|c|c|c|c|c|}
\hline \multirow[b]{2}{*}{ Nama senyawa } & \multicolumn{3}{|c|}{ Kriteria keberterimaan } & \multirow{2}{*}{$\begin{array}{r}\text { MDL } \\
(\mathrm{ng} / \mathrm{ml})\end{array}$} & \multirow{2}{*}{$\begin{array}{c}\text { LOQ } \\
(\mathrm{ng} / \mathrm{ml})\end{array}$} \\
\hline & Presisi & Akurasi & Reprodusibilitas & & \\
\hline 2-monoCB (1) & $\sqrt{ }$ & $\sqrt{ }$ & $\sqrt{ }$ & 3 & 7 \\
\hline 2,3-diCB (5) & $\sqrt{ }$ & $\sqrt{ }$ & $\sqrt{ }$ & 2 & 6 \\
\hline 2,4,6-triCB (30) & $\sqrt{ }$ & $\sqrt{ }$ & $\sqrt{ }$ & 1 & 3 \\
\hline 2,2',5-triCB (18) & $\sqrt{ }$ & $\sqrt{ }$ & $\sqrt{ }$ & 1 & 3 \\
\hline 2,4,5-triCB (31) & $\sqrt{ }$ & $\sqrt{ }$ & $\sqrt{ }$ & 3 & 10 \\
\hline 2,2',5,5'-tetraCB (52) & $\sqrt{ }$ & $\sqrt{ }$ & $\sqrt{ }$ & 7 & 20 \\
\hline 2,2',3,5-tetraCB (44) & $\sqrt{ }$ & $\sqrt{ }$ & $\sqrt{ }$ & 2 & 5 \\
\hline 2,3,4,4’'tetraCB (66) & $\sqrt{ }$ & $\sqrt{ }$ & $\sqrt{ }$ & 4 & 12 \\
\hline 2,2',4,5,5'-pentaCB (101) & $\sqrt{ }$ & $\sqrt{ }$ & $\sqrt{ }$ & 2 & 5 \\
\hline 2,2',3,4,5-pentaCB $(87)$ & $\sqrt{ }$ & $\sqrt{ }$ & $\sqrt{ }$ & 3 & 7 \\
\hline 2,3,3',4,6-pentaCB (110) & $\sqrt{ }$ & $\sqrt{ }$ & $\sqrt{ }$ & 3 & 7 \\
\hline 2,2’,3,5,5’,6-hexaCB (151) & $\sqrt{ }$ & $\sqrt{ }$ & $\sqrt{ }$ & 2 & 6 \\
\hline $2,2^{\prime}, 4,4^{\prime}, 5,5^{\prime}$-hexaCB (153) & $\sqrt{ }$ & $\sqrt{ }$ & $\sqrt{ }$ & 2 & 6 \\
\hline 2,2',3,4,5,5'-hexaCB (141) & $\sqrt{ }$ & $\sqrt{ }$ & $\sqrt{ }$ & 2 & 6 \\
\hline 2,2',3,4,4',5-hexaCB (138) & $\sqrt{ }$ & $\sqrt{ }$ & $\sqrt{ }$ & 2 & 6 \\
\hline 2,2',3,4,5,5',6-heptaCB (187) & $\sqrt{ }$ & $\sqrt{ }$ & $\sqrt{ }$ & 2 & 6 \\
\hline 2,2',3,4,4',5,6-heptaCB (183) & $\sqrt{ }$ & $\sqrt{ }$ & $\sqrt{ }$ & 4 & 12 \\
\hline 2,2',3,4,4',5,5'-heptaCB (180) & $\sqrt{ }$ & $\sqrt{ }$ & $\sqrt{ }$ & 2 & 5 \\
\hline $2,2^{\prime}, 3,3^{\prime}, 4,4^{\prime}, 5$-heptaCB (170) & $\sqrt{ }$ & $\sqrt{ }$ & $\sqrt{ }$ & 3 & 9 \\
\hline $2,2^{\prime}, 3,3^{\prime}, 4,4^{\prime}, 5,5^{\prime}, 6$-nonaCB (206) & $\sqrt{ }$ & $\sqrt{ }$ & $\sqrt{ }$ & 2 & 6 \\
\hline DecaCB (209) & $\sqrt{ }$ & $\sqrt{ }$ & $\sqrt{ }$ & 2 & 4 \\
\hline
\end{tabular}

dari 21 senyawa PCBs dalam matriks ikan berkisar antara 3-20 ng/ml. Baku mutu PCBs dalam biota belum tersedia.

\section{Simpulan}

Hasil validasi metode dari modifikasi USEPA metode 8082A dan Method 3541 menunjukkan bahwa dari total 21 congener PCBs yang diujikan, sebagian besar memenuhi syarat keberterimaan validasi, yaitu 18 congener dalam sampel air, 19 congener dalam sampel padatan dan 21 congener pada sampel biota.

\section{Ucapan Terima Kasih}

Penulis mengucapkan terima kasih kepada The Global Environment
Facility (GEF)-UNIDO dan Direktorat Pengelolaan Bahan Beracun Berbahaya (PB3), Kementerian Lingkungan Hidup dan Kehutanan (KLHK) atas pendanaan kegiatan, kepada PSIKLH atas fasilitas laboratorium dan sumber daya, Koperasi Pegawai Republik Indonesia Lingkungan Lestari (KPRI-LL), kepada Sdr. Ribbialif Wiga Fathullah, Sdr. Orinnisa Elfa Sabila, seluruh anggota tim, serta siswa Praktek Kerja Lapang di laboratorium tanah dan limbah padat yang mendukung kegiatan ini.

\section{Kepengarangan}

Seluruh anggota tim penulis berkontribusi sesuai dengan keahlian masing-masing dan menjadi suatu 
kesatuan yang tidak terpisahkan. Penulis pertama sebagai penanggungjawab kegiatan, konseptor, dan melakukan verifikasi data, penulis kedua mengumpulkan pustaka dan menyusun naskah, sementara penulis ketiga dan keempat melakukan kegiatan pengujian serta mengolah seluruh data.

\section{Daftar Pustaka}

Altan, C. O., \& Turan, H. (2016). Synergistic effect of freezing and irradiation on Bonito Fish (Sarda sarda Bloch, 1793). Journal of food protection, 79(12), 2136-2142.

Ananthu, S., \& Singh, J. K. (2018). Development and quality evaluation of noodles prepared from wheat flour supplemented with tamarind kernel powder. International Journal of Scientific Research in Science and Technology, 4(7), 285-293.

Antony Jesu Prabhu, P., Schrama, J., Fontagné Dicharry, S., Mariojouls, C., Surget, A., Bueno, M., . . . Kaushik, S. J. (2018). Evaluating dietary supply of microminerals as a premix in a complete plant ingredient-based diet to juvenile rainbow trout (Oncorhynchus mykiss). Aquaculture Nutrition, 24(1), 539547.

AOAC. (2016). Guidelines for standard method performance requirements Appendix $F$. Rockville, MD: AOAC International.

ATSDR. (2000). Toxicological profile for Polychlorinated Biphenyls(PCBs). Atlanta, Georgia: ATSDR.

Azis, M. Y., Setiyanto, H., Salim, A., Vita Hidayati, N., Asia, L., Piram, A., . . Syakti, A. D. (2021). Evidence of Micropollutants in sediment and mud clams (Polymesoda erosa) from one of mangrove biodiversity hotspots in Indonesia. Polycyclic Aromatic Compounds, 1-18. doi:10.1080/10406638.2 021.1901127.

Batang, Z. B., Alikunhi, N., Gochfeld, M., Burger, J., Al-Jahdali, R., Al-Jahdali, H., . . . Al-Suwailem, A. (2016). Congener-specific levels and patterns of polychlorinated biphenyls in edible fish tissue from the central
Red Sea coast of Saudi Arabia. Science of the Total Environment, 572, 915-925.

Bouhroum, R., Boulkamh, A., Asia, L., Lebarillier, S., Halle, A. T., Syakti, A. D., . . . WongWah-chung, P. (2019). Concentrations and fingerprints of PAHs and PCBs adsorbed onto marine plastic debris from the Indonesian Cilacap coast and theNorth Atlantic gyre. Regional Studies in Marine Science, 29, 100611. doi:https://doi.org/10.1016/j. rsma.2019.100611

BSN. (2017). SNI ISO/IEC 17025:2017 Persyaratan umum kompetensi laboratorium pengujian dan laboratorium kalibrasi. Jakarta: BSN.

Daud, N. S. M., Zaidel, D. N. A., Lai, K. S., Khairuddin, N., Jusoh, Y. M. M., \& Muhamad, I. I. (2018). Crude oil yield and properties of rice bran oil from different varieties as affected by extraction conditions using soxhterm method. Arabian Journal for Science and Engineering, 43(11), 62376244.

Đurović, S., Zeković, Z., Šorgić, S., Popov, S., Vujanović, M., \& Radojković, M. (2018). Fatty acid profile of stinging nettle leaves: application of modern analytical procedures for sample preparation and analysis. Analytical Methods, 10(9), 1080-1087.

Edward, E. (2016). Kontaminasi senyawa poliklorobifenil (PCB) pada kerang hijau, Perna viridis dari Teluk Jakarta. DEPIK Jurnal Ilmu-Ilmu Perairan, Pesisir dan Perikanan, 5(1).

Gunawan, H., Budianto, E., \& Soelarno, W. (2020). Penentuan batas konsentrasi PCBs pada minyak tranformator dengan metode analytical hierarchy process. Journal Industrial Services, 5(2).

Hens, B., \& Hens, L. (2018). Persistent threats by persistent pollutants: Chemical nature, concerns and future policy regarding PCBswhat are we heading for? Toxics, 6(1), 1 .

Hu, D., Martinez, A., \& Hornbuckle, K. C. (2011). Sedimentary records of non-Aroclor and Aroclor PCB mixtures in the Great Lakes. Journal of Great Lakes Research, 37(2), 359-364. 
Ilyas, M., Sudaryanto, A., Setiawan, I. E., Riyadi, A. S., Isobe, T., Ogawa, S., . . Tanabe, S. (2011). Characterization of polychlorinated biphenyls and brominated flame retardants in surface soils from Surabaya, Indonesia. Chemosphere, 83(6), 783-791.

KLHK. (2001). Peraturan Pemerintah No. 74/2001 tentang pengelolaan bahan berbahaya dan beracun. Jakarta.

Loganathan, B. G., \& Masunaga, S. (2020). PCBs, dioxins, and furans: human exposure and health effects Handbook of toxicology of chemical warfare agents (pp. 267-278): Elsevier.

Lush,L., Ward,A. I., \& Wheeler,P.(2014). Opposing effects of agricultural intensification on two ecologically similar species. Agriculture, ecosystems \& environment, 192, 61-66.

Norström, K., Czub, G., McLachlan, M. S., Hu, D., Thorne, P. S., \& Hornbuckle, K. C. (2010). External exposure and bioaccumulation of PCBs in humans living in a contaminated urban environment. Environment International, 36(8), 855-861.

Ogata, Y., Takada, H., Mizukawa, K., Hirai, H., Iwasa, S., Endo, S., . . . Nakashima, A. (2009). International pellet watch: Global monitoring of persistent organic pollutants (POPs) in coastal waters. 1. Initial phase data on PCBs, DDTs, and HCHs. Marine Pollution Bulletin, 58(10), 1437-1446.

Poornima, D., Hanumantharaju, K., Siva Shankar, V., Suresh Kumar, K., \& Ramya, H. (2019). Influence of moisture content and temperature on mechanical extraction of oil from watermelon (Citrullus lanatus) seeds. Journal of Pharmacognos and Phytochemistry, 8(4), 275-279.

Reddy, A. V. B., Moniruzzaman, M., Madhavi, G., \& Aminabhavi, T. M. (2020). Modern approaches in separation, identification and quantification of polychlorinated biphenyls. Current Opinion in Environmental Science \& Health, 18, 26-39.
Robertson, L. W., \& Hansen, L. G. (2014). PCBs: Recent advances in environmental toxicology and health effects.

Shoiful, A., Nugroho, R., Fujita, H., \& Honda, K. (2014). Konsentrasi Polychlorinated Biphenyls (Pcbs) dan Polychlorinated Dibenzo-p-dioxins/polychlorinated Dibenzofurans (Pcdds/fs) dalam Air dari Daerah Perkotaan Jabodetabek. Jurnal Air Indonesia, 7(1).

Shorstkii, I., Khudyakov, D., \& Mirshekarloo, M. S. (2020). Pulsed electric field assisted sunflower oil pilot production: Impact on oil yield, extraction kinetics and chemical parameters. Innovative Food Science \& Emerging Technologies, 60, 102309.

Silvani, L., Hjartardottir, S., Bielská, L., Škulcová, L., Cornelissen, G., Nizzetto, L., \& Hale, S. E. (2019). Can polyethylene passive samplers predict polychlorinated biphenyls (PCBs) uptake by earthworms and turnips in a biochar amended soil? Science of the Total Environment, 662, 873-880.

SNI. (2008). SNI 6989.59:2008 Air dan air limbah - Bagian 59: Metoda pengambilan contoh air limbah. Jakarta: BSN.

SNI. (2018). SNI 8520:2018 Cara pengambilan contoh uji limbah $B 3$ padat. Jakarta: BSN.

Travis, C. C., \& Hester, S. T. (1991). Global chemical pollution. Environmental science \& technology, 25(5), 814-819.

UN. (2011). Stockholm Convention on Persistent Organic Pollutants. Paper presented at the Stockholm Convention. 